\title{
Shift Work: Impact on Nurses' Health and Quality Life in Pointe-Noire (Congo)
}

\author{
Ebenguela Ataboho Ebatetou ${ }^{1,2 *}$, Patricia Atipo-Galloye ${ }^{3}$, Donatien Moukassa ${ }^{2}$ \\ ${ }^{1}$ Department of Occupational Medicine, TOTAL EP CONGO Clinic, Pointe-Noire, Congo \\ ${ }^{2}$ Faculty of Health Sciences, Marien Ngouabi University, Brazzaville, Congo \\ ${ }^{3}$ Faculty of Medicine, Pharmacy and Odontostomatology, Cheikh Anta Diop University, Dakar, Senegal \\ Email: ^ebatetou@gmail.com
}

How to cite this paper: Ebatetou, E.A., Atipo-Galloye, P. and Moukassa, D. (2021) Shift Work: Impact on Nurses' Health and Quality Life in Pointe-Noire (Congo). Open Journal of Epidemiology, 11, 16-30. https://doi.org/10.4236/ojepi.2021.111002

Received: November 13, 2020

Accepted: December 14, 2020

Published: December 17, 2020

Copyright $\odot 2021$ by author(s) and Scientific Research Publishing Inc. This work is licensed under the Creative Commons Attribution International License (CC BY 4.0).

http://creativecommons.org/licenses/by/4.0/

\begin{abstract}
Introduction: The consequences of shift work on health, psychological balance and socio-family life are multiple and universally known. Objective: The aim of this survey was to describe the impact of shift work on nurses' health and quality life. Methodology: This was a cross-sectional descriptive study of the exposed and non-exposed type from May 2013 to July 2013, i.e. for a period of 3 months. We had included and divided into two groups the nurses working in the various departments of the Loandjili General Hospital (LGH). A questionnaire derived from the Pittsburgh Sleep Quality Index and the Epworth Sleepiness Scale had been used to collect the data. Results: Of the 91 nurses considered, including 59 in shift work (group I) and 32 in daytime work (group II), significant associations were found between shift work on the one hand and sleep problems on the other hand in all these aspects, stress and appetite disturbances. However, no significant association was found between shift work on the one hand and the use of sleeping pills on the other hand. Fatigue, mood disorders and the notion of free time (at home and for leisure), although the frequencies are relatively high in the group of nurses on shift work. Conclusion: Our results show that nurses' health, social and family life at Loandjili General Hospital are negatively impacted by shift work. There is a need to put in place means of prevention.
\end{abstract}

\section{Keywords}

Shift Work, Nurses, Effects on Health, Quality of Life

\section{Introduction}

Industrial and economic requirements impose many work organizations in terms of rhythms and schedules. Currently, shift work affects $15 \%$ to $20 \%$ of the working population in developed countries [1] [2] [3]. However, all the impacts on 
the health of an employee in flexible hours and night shifts are still not yet fully understood [2].

The consequences of shift work on health, psychological balance, and socio-family life are numerous: sleep problems, vigilance, mood, cardiovascular disease, cancer, weight gain, metabolic and digestive problems, menstrual cycle disturbance, the procedures for pregnancy, occupational and traffic accidents [4]

From a point of view of regulation, the shift and/or night work of nurses is not specifically described. It is incorporated into the general legislation on night work, defined as a paid activity performed between 8 p.m. and 5 a.m. (art. 106 of the Congolese Labor Code) [5].

The notion of permanence of services and particularly medical care has full significance in a hospital environment. The nurses take turns in shifts: the day shifts give way to the night shift in the evening, after a period of 15 to 30 minutes of transmission and the reverse occurs in the morning. Night work is carried out in a fixed position or in alternating day/night mode. Nurses on shift schedules are also victims of disparities in the management of their working time towards day nurses: on night shifts, they work 12 hours a night while a day lasts on average 8 hours. On the other hand, the organization of working time in three shifts implies overlaps between the shifts.

In the United States, Europe and Asia, sleep problems caused by shift or night work in hospitals have been reported to affect work performance on most nurses [6] [7] [8] [9] [10]. However, in sub-Saharan Africa, few or none of surveys has been done on the relationship between shift or night work and nursing profession. Thus, we carried out this work in Pointe-Noire, Congo, at the Loandjili General Hospital (LGH), aiming to describe the impact of shift work on nurses' health and quality of life.

\section{Methodology}

\subsection{Setting, Type and Surveyed Population}

Our survey took place at Loandjili General Hospital (LGH). We carried out a descriptive and cross-sectional survey of exposed, non-exposed type from May 2013 to July 2013, or a period of three (3) months.

The surveyed population was made up of nurses working in hospital emergency departments, the outpatient and outpatient department and inpatient departments, present at the time of the survey and who agreed to complete the questionnaire. We divided the nurses retained into two (2) groups:

- Group I (GI) for exposed, that is to say nurses with a shift rhythm $(3 \times 8$ or 2 $\times 12$ ).

- Group II (GII) for those not exposed, that is to say nurses working fixed hours from 7 a.m. to 2 p.m. from Monday to Friday.

\subsection{Survey Methods}

\subsubsection{Procedure}

In each department, the investigation was managed by the supervising nurse of 
the department. The questionnaires were given to all nurses. The completed questionnaires were collected at the end of each week.

\subsubsection{Survey Variables}

The various data of the survey were collected from the French version of the Pittsburgh Sleep Quality Index (PSQI) [11] (Appendix 1), whose assessment of the different components was classified according to a Likert and EPWORTH Sleepiness Scale (ESS) [12] for the assessment of excessive daytime sleepiness, depending on whether the score ranged from 0 to 24 (Appendix 2). The person was considered to have excessive daytime sleepiness when his score was greater than or equal to 15 .

The different survey variables were: the epidemiological parameters of the surveyed population (age, sex, marital status, seniority and seniority on shift work), parameters linked to the impact of shift work on health: average sleep time, sleep quality, sleep depth, sleep efficiency, sleep satisfaction, excessive daytime sleepiness, use of sleeping pills, fatigue, stress, mood problems, appetite disturbance and parameters related to life quality, in particular free time at home and real leisure time.

\section{1) Bias}

The selection criteria were established in order to avoid bias in the interpretation of the results. The non-inclusion of nurses from LGH, who have secondary jobs in other local medical centers made it possible to avoid taking into account impacts on health due to the summation of both jobs.

\section{2) Statistical analysis}

We used Graphpad Prism version 5.0.0.288 and Microsoft Excel version 8 data processing software for data processing and graphing.

The calculation of the position (median and mean) and dispersion (minimum, maximum, variance and standard deviation) parameters of the quantitative variables, as well as that of the frequencies for the qualitative variables constituted the univariate analysis of our survey. The bivariate analysis was done by calculating $\mathrm{p}$-values with the data comparison program which uses the chi2 test for the qualitative variables and the t-test for the quantitative variables. The $\mathrm{p}$-value confirms that there is a significant difference between two numbers or two averages. In this case, its value should be less than or equal to 0.05 .

\section{Results}

\subsection{Epidemiological Parameters of the Surveyed Population}

During the survey period, Loandjili General Hospital (LGH) had 174 nurses, or 133 (76.4\%) worked shift and 41 (23.6\%) worked daytime. The selection criteria enabled consider 91 (52.3\%) nurses, including 59 shift work nurses and 32 daytime nurses, i.e. $44.4 \%$ of shift work nurses and $78.1 \%$ of daytime nurses, respectively.

The univariate analysis of all the epidemiological parameters of our surveyed population is shown in Table 1 . The age extremes are 25 and 53 years with a 
Table 1. Breakdown of socio-demographic and professional characteristics.

\begin{tabular}{|c|c|c|c|c|}
\hline & \multicolumn{2}{|c|}{ Group I* } & \multicolumn{2}{|c|}{ Group $\mathrm{II}^{* *}$} \\
\hline & Effective & Percentage & Effective & Percentage \\
\hline \multicolumn{5}{|c|}{ Age (years) } \\
\hline $25-34$ & 27 & 45.8 & 8 & 25.0 \\
\hline $35-44$ & 25 & 42.4 & 12 & 37.5 \\
\hline $45-54$ & 7 & 11.8 & 12 & 37.5 \\
\hline Total & 59 & 100 & 32 & 100 \\
\hline \multicolumn{5}{|l|}{ Sex } \\
\hline Male & 24 & 40.7 & 11 & 34.4 \\
\hline Feminine & 35 & 59.3 & 21 & 65.6 \\
\hline \multicolumn{5}{|c|}{ Marital status } \\
\hline Married & 17 & 28.8 & 14 & 43.8 \\
\hline Single & 42 & 71.2 & 18 & 56.2 \\
\hline \multicolumn{5}{|l|}{ Seniority } \\
\hline $1-5$ & 14 & 23.7 & 7 & 21.9 \\
\hline $6-10$ & 33 & 55.9 & 13 & 40.6 \\
\hline$>10$ & 59 & 20.4 & 12 & 37.5 \\
\hline \multicolumn{5}{|c|}{ Seniority at shift work } \\
\hline $1-5$ & 19 & 32.2 & & \\
\hline $6-10$ & 35 & 59.3 & & \\
\hline$>10$ & 5 & 8.5 & & \\
\hline
\end{tabular}

${ }^{\star}$ Group I: Nurses in shiftwork), ${ }^{*}$ Group II: nurses in daytime.

median equal to 37 and a middle of age $37.72 \pm 6.99$ years old. The sex ratio (F/M) was 1.6.

The majority of the population was single (65.9\%).

Seniority in the nursing profession for the entire survey sample with extremes of 1 to 30 years, a median equal to 9 years and an average equals to $10.3 \pm 7.4$ years. As for seniority on shift work, the extremes were 1 to 20 years, the median equal to 7 years and the average equals to $7.0 \pm 3.9$ years.

\subsection{Impact of Shift Work on Nurses' Sleep}

The quality of sleep was good for $6.8 \%$ of nurses on duty compared to $31.3 \%$ of their day shift colleagues. The sleep quality was quite bad for $45.8 \%$ of shift nurses compared to $15.6 \%$ of the day shift nurses.

The depth of sleep was considered fairly bad for $66.1 \%$ of shift nurses, while $53.1 \%$ of day nurses reported to have a fairly good depth of sleep.

Nurses in Group I were only $1.7 \%$ to have good sleep efficiency compared to $31.3 \%$ of day nurses. In return, $40.7 \%$ of nurses on duty reported that their sleep 
efficiency was quite poor compared to $12.5 \%$ in the day nurses group.

The sleep satisfaction was good for $5.1 \%$ of shift nurses compared to 21.9 among day nurses.

Sleep satisfaction was good in $5.1 \%$ of the shift nurses compared to $21.9 \%$ of the daytime nurses.

All the differences observed above were significant (Table 2). Regarding the overall duration of sleep, nurses working shift schedules slept about 1 hour less than their colleagues who only work daytime: $6.3 \pm 0.2$ hours versus $7.1 \pm 0.2$ hours $(\mathrm{p}=0.0305)$.

Finally, in the population of nurses working shift schedules, $86.4 \%$ stated that they had never taken medication to sleep against $13.6 \%$ who had taken sleeping pills during the last months. On the other hand, among daytime nurses, $90.6 \%$ had never taken sleeping pills against $9.4 \%$ who had taken them during the last months. The differences observed between the two (2) groups are not statistically significant $(\mathrm{p}=0.495)$.

Table 2. Distribution of groups of nurses according to sleep problems.

\begin{tabular}{|c|c|c|c|c|c|}
\hline \multirow{2}{*}{ Characteristics } & \multicolumn{2}{|c|}{ Group I } & \multicolumn{2}{|c|}{ Group II } & \multirow{2}{*}{$\mathrm{p}$} \\
\hline & Effective & $\%$ & Effective & $\%$ & \\
\hline \multicolumn{6}{|l|}{ Sleep quality } \\
\hline Good & 4 & 6.8 & 10 & 31.3 & \multirow{4}{*}{0.0019} \\
\hline Fairly good & 26 & 44.1 & 17 & 53.1 & \\
\hline Fairly bad & 27 & 45.8 & 5 & 15.6 & \\
\hline $\mathrm{Bad}$ & 2 & 3.4 & 0 & 0.0 & \\
\hline \multicolumn{6}{|l|}{ Sleep depth } \\
\hline Good & 2 & 6.3 & 4 & 6.8 & \multirow{4}{*}{0.0007} \\
\hline Fairly good & 11 & 18.6 & 17 & 53.1 & \\
\hline Fairly bad & 39 & 66.1 & 9 & 28.1 & \\
\hline $\mathrm{Bad}$ & 7 & 11.9 & 2 & 6.3 & \\
\hline \multicolumn{6}{|l|}{ Sleep efficiency } \\
\hline Good & 1 & 1.7 & 10 & 31.3 & \multirow{4}{*}{0.0012} \\
\hline Fairly good & 26 & 44.1 & 15 & 46.9 & \\
\hline Fairly bad & 24 & 40.7 & 4 & 12.5 & \\
\hline $\mathrm{Bad}$ & 8 & 13.6 & 3 & 9.4 & \\
\hline \multicolumn{6}{|c|}{ Satisfaction with sleep } \\
\hline Good & 3 & 5.1 & 7 & 21.9 & \multirow{5}{*}{0.0035} \\
\hline Fairly good & 19 & 32.2 & 17 & 53.1 & \\
\hline Fairly bad & 28 & 47.5 & 6 & 18.8 & \\
\hline $\mathrm{Bad}$ & 9 & 15.3 & 2 & 6.3 & \\
\hline Total & 59 & 100 & 32 & 100 & \\
\hline
\end{tabular}


As for excessive daytime sleepiness, it was found at a frequency of $44.1 \%$ for nurses in GI against 21.9\% for nurses in GII ( $\mathrm{p}=0.0419)$.

Finally, in the population of nurses working shift schedules, $86.4 \%$ said they had never taken sleeping medication compared to $13.6 \%$ who had taken sleeping pills in recent months. In contrast, $90.6 \%$ of day nurses had never taken sleeping pills compared to $9.4 \%$ who had taken them in the past few months. The differences observed between the two (2) groups are statistically not significant ( $\mathrm{p}=$ $0.495)$.

\subsection{Other Effects of Shift Work on Nurses' Health}

\subsubsection{Fatigue}

Nearly half of nurses on shift work $(45,76 \%)$ claimed to be often tired compared to $28.13 \%$ of nurses on daytime shifts ( $p=0.0968$ ).

\subsubsection{Stress}

In our study, we found a very high frequency of stress for nurses in group I $(40.68 \%)$ against $25 \%$ for nurses in group II nurses $(\mathrm{p}=0.0285)$ as shown in Figure 1.

\subsubsection{Mood Problems}

In our series, around $30 \%$ of shift nurses claimed to have had a bad mood in recent months compared to $12.50 \%$ of daytime nurses $(\mathrm{p}=0.2269$ ).

\subsubsection{Appetite Problems}

In our work, more than half (50.9\%) of nurses on shift schedules claimed to have appetite problems such as lack, or loss of appetite compared to $21.9 \%$ of daytime nurses $(\mathrm{p}=0.0008)$.

\subsection{Quality of Life Disturbances}

$61.0 \%$ of nurses on shift schedules found their free time at home insufficient ( $\mathrm{p}$ $=1$ ) versus $62.5 \%$ of daytime nurses.

As for their real leisure time, $81.4 \%$ of shift nurses also found it insufficient, as did $68.8 \%$ of their day colleagues $(\mathrm{p}=0.1989)$.

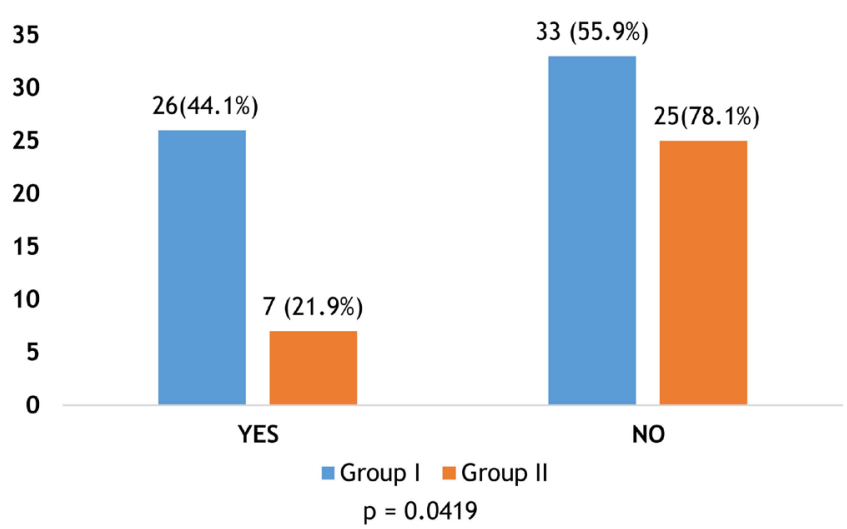

Figure 1. Distribution of nursing groups according to stress level. 


\section{Discussion}

The realization of this study was confronted with certain limits in particular the mismatch on the real number of nurses working at the Loandjili General Hospital. The documents received by the nursing directorate and human resources departments did not provide data. The study retained as the total number of nurses, that provided by the Nursing Department which is the user of resources made available. Besides this, local or African bibliographic references on the matter are rare or almost non-existent despite the Medline search strategy. Comparisons were only made with American, European and Asian references, notwithstanding the significant differences in lifestyles.

Our study has found a relatively young population of shift nurses; the average age was 35.68 years. Gold and al, in his work had an average age compared to ours (35 years) in the group of shift nurses [6]. On the other hand, Shen et al., who studied effects of shift work in a general population of employees, has found an average age of 42.1 years among shift employees [13]. This difference in average age between the general population and that of nurses can be explained by the fact that the option of working nights or alternating hours in hospitals often depends on seniority. Young nurses are generally assigned to rotating shifts and older nurses to day shifts.

On this point, many studies show a better tolerance of shift work among young employees than among older ones [7] [14] [15] [16].

The female predominance in both groups only confirms the feminization of the nursing profession. In this regard, the literature shows that women complain much more than men about troubles linked to shift work [14] [15].

Data from the literature show a better adaptation to shift work among single people than among employees living together as a couple. In the latter, partner labor is often a source of secondary complications [17] [18].

There is little longitudinal data on the effect of tenure. However, some studies show an increase in the relative risk of developing a cardiovascular disease beyond 5 years of sentant in shift work [1] [4], an irreversibility of sleep problems linked to shift work beyond 20 years. years and an increased risk of developing breast cancer among nurses who have practised 20 years or more in a rotating system compared to nurses who have worked only daytime all their lives [4].

In our series, we have found sleep disturbances among LGH nurses on shift schedules with very significant differences compared to nurses of the day. These disturbances included average sleep duration, sleep quality, sleep depth, sleep efficiency, sleep satisfaction and excessive daytime sleepiness. In the literature, studies have also found a decrease in the average sleep time among employees shifted for 1 - 2 hours compared to the sleep time of day employees [19] [20] [21] [22]. On the other hand, some series do not find a significant difference between the average duration of sleep among shift and/or night employee and that of day employees: $6.61 \pm 1.5$ vs $6.8 \pm 1.2$ for Drake and al [23] and $5.9 \pm 1.2$ 
vs $6 \pm 0.9$ for Ohida et al. [24].

Regarding the quality of sleep, Pilcher et al. [19] found frequencies quite close to ours in young Japanese nurses: $42 \%$ and $7 \%$. In addition, Gold et al. [6] noticed poor quality of sleep in $52.1 \%$ of nurses on rotating schedules and in $27.8 \%$ of day nurses.

The authors are unanimous on the fact that the sleep of the shift employee is deeply disturbed concerning its efficiency, depth and satisfaction [11] [14] [18] [24] [25].

Regarding excessive daytime sleepiness, studies have also found an increased risk of excessive daytime sleepiness for shift and/or night employees [7] [8] [26] [27]. This would be attributable to the long duration of duties and to an almost chronic debt of sleep.

As in our series, Gold et al. [6] also notice that nurses on alternating schedules consume much more sleeping pills $(27.7 \%)$ than their colleagues who work only daytime (16.5\%).

Overall, we noticed as a function of the adopted shift work rhythm, sleep is disturbed quantitatively and qualitatively [4] [18] [24] in the same way. The differences observed may be due to the type of epidemiological studies chosen.

Several studies [1] [13] [14] [18] [25] [28] show that chronic fatigue is one of the most common complaints among shift employees. It is often notified after a night shift. However, its assessment objectively is still difficult to measure.

Shift work can be a potential stressful element due to sleep deprivation, long working hours, chronic tiredness and the rupture of social and family contacts it generates. A study carried out on 286 Finnish nurses also found more symptoms of stress in employees at alternating pace [17].

Mood problems such as depression, anxiety and irritability represent short-term health effects of shift work [28]. It is certain that insufficiently restful sleep is an important cause, but some authors invoke the role of certain character traits (such as introvert character) and job satisfaction [17].

A review of the literature found frequencies of appetite disturbances from $35 \%$ to $75 \%$ among shift employees and 50\% among night employees [25]. Appetite disturbances in shift employees arise from changing normal meal times, difficulty having hot food at night, and inability to have social contact during the meal with family or friends. Sleep problems also play an important role [4] [18] [25].

Shift or night employees are frequently out of step with their society, and have to face great challenges in their social life because the majority of family and social activities are arranged in accordance with the orientation of the rhythm of the general people's day. Therefore, shift work can lead to social marginalization due to the discrepancy between the little free time they have and the compound organization of social activities. This time pressure is a constant problem for those who have heavy family responsibility and can therefore have a negative influence on marital relationships, parenting and child rearing. 


\section{Conclusion}

Shift work has become unavoidable in the operation of any hospital center. This way of working generates or is likely to make worse various health problems well known nowadays. Sleep problems, stress and appetite disturbances occupy a considerable place in the nursing population of Loandjili General Hospital. Its disturbances on the socio-family life of employees exposed to this type of rhythm are not the least. Thus, in order to prevent health and socio-family life problems linked to shift work, it should be put in place a careful monitoring of occupational physicians integrated into a medical care network including treating physicians, occupational psychologists and specialized sleep centers to control the inherent morbidity to extrinsic disturbances of the circadian rhythm.

\section{Conflicts of Interest}

The authors declare no conflict of interest in relation to this article.

\section{References}

[1] Ntawaruhunga, E, Chouanière, D., Danuser, B. and Praz-Christinaz, S.M. (2008) Effects of Night Work on Health. Revue Médicale Suisse, 4, 2581-2585.

[2] Bayon, V., Prevot, E. and Leger, D. (2009) Shiftwork and Cancer. Sleep Medicine, 6, 25-30. https://doi.org/10.1016/j.msom.2009.02.004

[3] From Bacquer, D.Van Resseghem, M. and Clays, E. (2009) Rotating Shift Work and the Metabolic Syndrome: A Prospective Study. International Journal of Epidemiology, 38, 848-854. https://doi.org/10.1093/ije/dyn360

[4] Christmas, S. (2009) The Morbidity of Working Irregular Hours. Revue Medicale de Bruxelles, 30, 309-317.

[5] Congolese Labor Code (1996) Law No. 45 of March 15, 1975, Modified by Laws No. 22-88 of September 17, 1988 and No. 6-96 of March 6, 1996 Title 4 Relating to Working Conditions. Chapter 2: Night Work. Congolese Labor Code, Congo, 23.

[6] Gold, D.R., Rogacz, S., Bock, N., Tosteson, T.D., Baum, T.M., Speizer, F.E., and Czeisler, C.A. (1992) Rotating Shift Work, Sleep, and Accidents Related to Sleepiness in Hospital Nurses. American Journal of Public Health, 82, 1011-1014. https://doi.org/10.2105/AJPH.82.7.1011

[7] Anbazhagan, S., Ramesh, N., Nisha, C. and Joseph, B. (2016) Shift Work Disorder and Related Health Problem among Nurses Working in a Tertiary Care Hospital, Banglore, South India. Indian Journal of Occupational and Environmental Medicine, 20, 35-38. https://doi.org/10.4103/0019-5278.183842

[8] Eldevik, M.F., Flo, E., Moen, B.E., Pa llesen, S., Bjorvatn, B. (2013) Insomnia, Excessive Sleepiness, Excessive Fatigue, Anxiety, Depression and Shift Work Disorder in Nurses Having Less than 11 Hours in-Between Shifts. PLoS ONE, 8, e770882. https://doi.org/10.1371/journal.pone.0070882

[9] Devore, E.E., Grodstein, F. and Schernhammer, E.S. (2013) Shift Work and Cognition in the Nurses' Health Study. American Journal of Epidemiology, 178, 1296-1300. https://doi.org/10.1093/aje/kwt214

[10] Lin, S.H., Liao, W.C., Chen, M.Y. and Fan, J.Y. (2014) The Impact of Shift Work on Nurses' Job Stress, Sleep Quality and Self-Perceived Health Status. Journal of Nursing Management, 22, 604-612. https://doi.org/10.1111/jonm.12020 
[11] Buysse, D., Reynolds, C., Monk, T., Berman, S.S. and Kupher, D. (1988) The Pittsburgh Sleep Quality Index: A New Instrument for Psychiatric Practice and Research. Psychiatry Research, 28, 193-213.

https://doi.org/10.1016/0165-1781(89)90047-4

[12] Award of the Label (2012) HAS Medico-Professional Surveillance of Shift and/or Night Workers. Method "Recommendations for Clinical Practice".

http://www.chu-rouen.fr/sfmt/autres/Reco HAS Travail poste-Texte court 30-05 -2012.pdf

[13] Shen, J.H., Botly, L.C.P., Chung, S.A., Gibbs, A.L., Sabanadzovic, S. and Shapiro, C.M. (2006) Fatigue and Shift Work. Journal of Sleep Research, 15, 1-5. https://doi.org/10.1111/j.1365-2869.2006.00493.x

[14] Harrington, J.M. (2001) Health Effects of Shift Work and Extended Hours of Work. Occupational and Environmental Medicine, 58, 68-72.

http://dx.doi.org/10.1136/oem.58.1.68

[15] Saksvik, I.B., Bjorvatn, B., Hetland, H., Sandal, G.M. and Pallesen, S. (2011) Individual Differences in Tolerance to Shift Work-A Systematic Review. Sleep Medicine Reviews, 15, 221-235. https://doi.org/10.1016/j.smrv.2010.07.002

[16] Loudoun, R.J., Muurlink, O., Peetz, D. and Murray, G. (2014) Does Age the Relationship between Control at Work Sleep Disturbance for Shift Workers? Chronobiology International, 31, 1190-1200. https://doi.org/10.3109/07420528.2014.957307

[17] Leonard, R. (1998) Work and Time. Work in Atypical Hours. National Institute for Research on Working Conditions, Brussels, 33, 72, 87-95, 115-116.

https://emploi.belgique.be/sites/default/files/content/publications/FR/88da10b5d06 148139d42335d49344d522.pdf

[18] Finn, P. (1981) The Effects of Shift Work on the Lives of Employees. Monthly Labor Review, 104, 31-35.

[19] Pilcher, J.J., Lambert, B.J. and Huffault, A.I. (2000) Differential Effects of Permanent and Rotating Shifts on Self-Report Sleep Length: A Meta-Analytic Review. Sleep, 23, 1-9. https://doi.org/10.1093/sleep/23.2.1b

[20] Ohayon, M.M., Lemoine, P., Arnaud-Briant, V. and Dreyfus, M. (2002) Prevalence and Consequences of Sleep Disorders in a Shift Worker Population. Journal of Psychosomatic Research, 53, 577-583. https://doi.org/10.1016/S0022-3999(02)00438-5

[21] Virtanen, M., Ferrie, J.E., Gimeno, D., Vahtera, J., Elovainio, M., Singh-Manoux, A., et al. (2009) Long Working Hours and Sleep Disturbances: The Whitehall II Prospective Cohort Study. Sleep, 32, 737-745. https://doi.org/10.1093/sleep/32.6.737

[22] Akerstedt, T. and Wright Jr., K.P. (2009) Sleep Loss and Fatigue in Shift Work and Shift Work Disorder. Sleep Medicine Clinics, 4, 257-271.

https://doi.org/10.1016/j.jsmc.2009.03.001

[23] Drake, L.C., Roehrs, T., Richardson, G., Walsh, J.K. and Roth, T. (2004) Shift Work Sleep Disorders: Prevalence and Consequences beyond That of Symptomatic Day Workers. Sleep, 27, 1453-1462. https://doi.org/10.1093/sleep/27.8.1453

[24] Ohida, T., Kamal, A.M.M., Sone, T., Ishii, T., Uchiyama, M., Minowa, M. and Nozaki, S. (2001) Night Shift Work Related Problems in Young Female Nurses in Japan. Journal of Occupational Health, 43, 150-156. https://doi.org/10.1539/joh.43.150

[25] Ladou, J. (1982) Health Effects of Shift Work. In Occupational Disease-New Vistas for Medecine. Western Journal of Medicine, 137, 525-530. 
[26] Härmä, M., Sallinen, M., Ranta, R., Mutanen, P. and Muller, K. (2002) The Effect of an Irregular Shift System on Sleepiness at Work in Train Drivers and Railway Traffic Controllers. Journal of Sleep Research, 11, 141-151. https://doi.org/10.1046/j.1365-2869.2002.00294.x

[27] Sallinen, M., Härmä, M., Mutanen, P., Ranta, R., Virkkala, J. and Müller, K. (2003) Sleep-Wake Rhythm in an Irregular Shift System. Journal of Sleep Research, 12, 103-112. https://doi.org/10.1046/j.1365-2869.2003.00346.x

[28] Costa, G. (2003) Shift Work and Occupational Medicine: An Overview. Occupational Medicine, 53, 83-88. https://doi.org/10.1093/occmed/kqg045 


\section{Appendix 1:}

\section{SURVEY FORM}

Date: Inclusion Number

1) General Information

Service

Age

Sex: Male $\square$ Female

Marital Status: Married

Single

Number of children:

Grade:

Fonction:

Senority:

2) Personal medical history (Pre shift work)

Tobacco: yes

Alcohol: yes no

Hypertension: yes

Diabetes: yes no

Gastrointestinal disorders: yes

Which one:

3) Shift work information

Shift work: yes no

Senority:

If yes Continuous $\square$ Semi-continuous

Discontinuous

Direstion of rotation: Forward Reverse

Type of rotation: Long $(>4 \mathrm{~d})$ Shord $(2-3 d)$ Fast (1 d)

Number of teams:

4) Informations on the health effects of shift work

a) Sleep and vigilance

i) $n$ the previous months, at what time on average did you go to bed (light off)

ii) In the previous months, on average, how long did it take you to fall asleep?

iii) In the previous months, on average, what time did you get up?

iv) In the past few months, based on your job type, how many hours of actual sleep per night, on average, did you get? (this number of hours may be different from the number of hours spent in bed)

v) In the past few months, has your sleep been:

- Good

- Fearly good

- Bad

- Fearly bad

vi) In the past months, has your sleep depth been: 
- Good

- Fearly good

- Bad

- Fearly bad

vii) During the past months, has your sleep efficiency (its restful nature) been:

- Good

- Fearly good

- Bad

- Fearly bad

viii) Overall, how satisfied are you with your primary sleep in recent months?

- Good

- Fearly good

- Bad

- Fearly bad

ix) In the past months, how would you rate your desire to sleep at bedtime?

- Very strong

- Strong

- Very weak

- Weak

$\mathrm{x})$ In the past few months, how often have you taken medication to help you sleep?

- Never

- Less than 1 time per month

- 1 to 2 times per month

- 3 or more times per month

b) Activities and general status

i) In the past few months, have you ever felt fatigued outside of work??

- Always

- Often

- Sometimes

- Rarely

- Never

ii) In the previous months and outside of your working hours, you have been feeling:

- Not at all energetic

- Energetic

- Very energetic

iii) In the previous months and outside of your working hours, you have been feeling

- Not stressed at all

- Stressed

- Very stressed

iv) In the previous months, you would say your general mood was:

- Very bad 
- $\mathrm{Bad}$

- Good

- Very good

v) In general, in the previous months, have you noticed any occurrence of:

- Appetite disorders: yes

- Digestive disorders: yes

- Palpitations: yes $\square$ no

- Hypertension: yes no

Weight problems: yes

- menstrual disorders: yes no

\section{5) Information on the risk of workplace accidents}

In the past months, during your working hours, have you been the victim of an accident at work: yes no If yes, have you been the victim of an accident at work:

6) Information on social life

a) Over the past few months, outside of work hours, how much free time do you feel you have at home?

- Insufficient

- Sufficient

b) During the previous months, outside of your working hours, how much time do you feel you have for real leisure activities?

- Insufficient

- Sufficient

\section{Appendix 2}

\section{EPWORTH SLEEPINESS SCALE}

Instructions: How likely are you to doze off or fall asleep in the following situations, apart from a simple feeling of fatigue?

Even if you haven't found yourself in such circumstances recently, imagine your reaction.

Use the following scale to choose the most appropriate number for each situation.

$$
\begin{aligned}
& 0=\text { no risk of dozing off } \\
& 1=\text { small chance of dozing off } \\
& 2=\text { average possibility of dozing off } \\
& 3=\text { great chance of dozing off }
\end{aligned}
$$

\section{Situations:}

Sitting while reading

While watching television

Sitting inactive in public (e.g. theater, cinema or meeting)

As a passenger in a car for one hour non-stop

Lying down in the afternoon to take a nap if circumstances allow it

\section{$\begin{array}{llll}0 & 1 & 2 & 3\end{array}$}
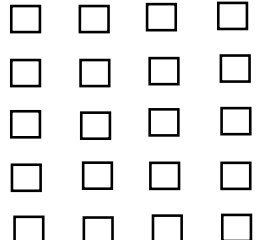
Sitting and talking with someone

Sitting quietly after an alcohol-free meal

In a car, after a few minutes stop in a traffic jam $\square \square \square \square$

$\square \square \square \square$

$\square \square \square \square$

Thank you for your cooperation 